\title{
Application of numerical ultimate analysis in identifying the bearing capacity of foundation
}

\author{
Tang Xiao-song ${ }^{1,2}$, Wang Yong-fü ${ }^{2}$, Deng Chu-jian ${ }^{3}$ \\ ${ }^{1}$ Chongqing Vocational College of Public Transportation, Department of Railway and Construction Engineering, Chongqing 402247, \\ China \\ ${ }^{2}$ Chongqing Institute of Geology and Mineral Resources, Chongqing Engineering Research Center of Automatic Monitoring for \\ Geological Hazards, Chongqing 400042, China \\ ${ }^{3}$ Engineering and Technology Research Center of Geological Hazard Prevention and Treatment, Chongqing 400041, China
}

\begin{abstract}
Load test is the main method to identify the bearing capacity of foundation in practical engineering. However, some problems are existing in the experiment, such as the scale effect, high cost and long construction period. The newly numerical ultimate analysis can overcome the shortcomings of timeconsuming, complicated operation, inaccuracy and so on, which is gradually becoming an effective calculation method in geo-technical engineering. The paper adopts increment loading method and ultimate strain method to simulated the load test numerically. The calculation examples in the paper show that the results of load test can be obtained through numerical ultimate analysis, where the ultimate strain method is better.
\end{abstract}

\section{Introduction}

The identification of bearing capacity of foundation is an classical topic of soil mechanics [1], which is directly related to the safety and cost of buildings. It is emphasized by the construction units, structural engineers and construction enterprises and studied by many researchers. Geo-technical engineering has much practicability, where the space-time variability and territoriality of geo-technical materials cause the evaluation of bearing capacity conducted empirically. So, it is very urgent to solve the problem of evaluating the bearing capacity of foundation. It is generally believed that the load test in the original location can simulate the initial stress state of rock and soil in various experiments of bearing capacity of foundations, where the parameters of bearing capacity are reliable and the potential bearing capacity can be found. So load test is often considered as the comparison basis of other experiments of bearing capacity. In practical engineering, loading experiment is often considered as the most authoritative solution when the data of bearing capacity of foundation is not available or reliable. It is also the worldwide major method in identifying the bearing capacity of foundation and is widely used in the effect inspection of foundation treatment. However, the high cost and long construction period of loading experiment make it uneasy to promote. And some problems exist if taking it as an model test of state of stress of foundation [2,3]. With the rapid development of geo-technical theories, modern calculation technology, hard and soft ware of computers,
FEM limit analysis is gradually becoming a practical calculation method in geo-technical engineering, because it can overcome the disadvantages of time-consuming, complicated operation and inaccuracy [4-6]. Based on this, the paper simulates numerically the load test through increment loading method and ultimate strain method.

\section{Basic principles}

\subsection{Basic principles of increment loading method}

In practical engineering, the failure of rock and soil mass is gradual which transits from the initial linear elastic state to the ultimate failure of plastic flow [7]. With the gradual increase of load, the rock and soil mass becomes plastic from elastic and then reaches the ultimate failure. At that moment, the corresponding load is the ultimate load. The increment loading method can reach the failure state through increasing load and its principle is similar with the above, so it is called FEM load increment method or FEM overload method.

\subsection{Basic principle of ultimate strain}

Geo-technical materials has the property of ultimate strain, whose value can be worked out through indoor experiment or numerical simulation $[4,5]$. If the strain of a certain point in the material reaches ultimate stain, failure would happen on this point in the material. Only

\footnotetext{
${ }^{*}$ Corresponding author's e-mail: hnm97@163.com
} 
when the failure on the points link to form a complete failure surface, the complete failure happens in the material. So the location where failure happens first is the location where crack appears, as a result, the safety factor of crack of the material can be obtained; when the failure of some points link to form a complete failure surface, the location of complete failure surface can be found so as to work out the stability safety factor of complete failure of the material. So the complete failure of the material can be obtained through traditional ultimate analysis method, FEM strength reduction based on complete failure and ultimate strain method based on point failure respectively. Although the failure criteria of the three methods are different, the basic assumptions are the same and the calculated complete safety factors are the same. So the ultimate strain method is correct and feasible.

\section{Calculating bearing capacity of foundations through load increment method}

\subsection{Test results and calculation parameters}

The experiment results of a certain point in the foundation after dynamic compaction are shown in table 1 and figure 1 . Before the pressure of $380 \mathrm{kPa}$ is imposed, the curve of pressure-settlement(p-s) is similar to a direct line. After the appearance of the first inflection point, the p-s curve increases to $960 \mathrm{kPa}$. The soil surrounding the bearing plate lifts when the pressure increases to $1.06 \mathrm{MPa}$, so the foundation soil reaches to failure and experiment ends. The curve at this moment becomes concave a little and the latter part of the curve is approximately direct, so the failure would happen after a while. The ultimate bearing capacity on this point is evaluated as $960 \mathrm{kPa}$ according to the standard. The corresponding settlement is $29.16 \mathrm{~mm}$ and the proportional limit load is $380 \mathrm{kPa}$. Since the proportional limit load is less than half of the ultimate bearing capacity, the eigenvalue of bearing capacity is $380 \mathrm{kPa}$.

Table 1. Relationship between pressure and displacement

\begin{tabular}{cccccccccc}
\hline Pressure $/ \mathrm{kPa}$ & 150 & 270 & 380 & 500 & 610 & 730 & 840 & 960 & 1060 \\
\hline Settlement $/ \mathrm{mm}$ & 2.69 & 5.14 & 8.12 & 12.41 & 16.38 & 20.74 & 24.98 & 29.16 & 33.20 \\
\hline
\end{tabular}

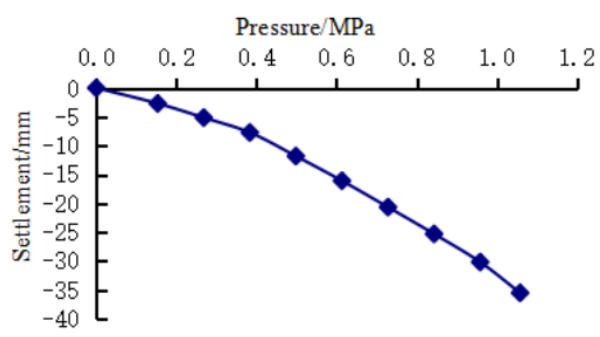

Figure 1. Pressure-settlement curve of experiment point

\subsection{FEM model and calculation parameters}

Round and rigid bearing plate is adopted in the experiment, so the model is axisymmetric. The FEM model and its grid subdivision are shown in figure 2. Yield criterion adopts round DP3 of the same area with $\mathrm{M}-\mathrm{C}$ and ideal plastic-elastic model should be used to work out the solution. The related parameters of the soil are: $\gamma=22 \mathrm{kN} / \mathrm{m}^{3}, \mathrm{c}=32.5 \mathrm{kPa}, \varphi=30.2^{\circ}$, poisson's ratio $v=0.27$, elastic modulus $\mathrm{E}=95 \mathrm{MPa}$.

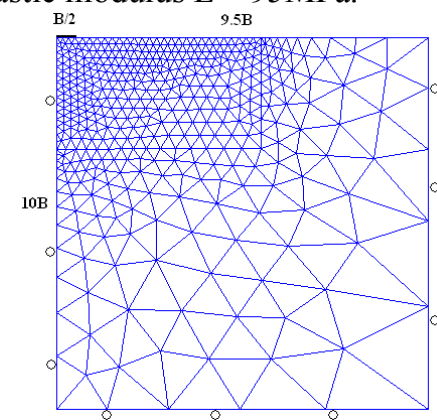

Figure 2. FEM model and its grid subdivision

\section{3 calculation results of load increment method}

The increment loading is used to simulate the test process. There are altogether 18 loading steps and the details are shown in table 2. The ultimate load is worked out through FEM increment loading method. Table 2 shows the process of imposing the load and table 3 shows the FEM calculation results of pressure and settlement on the experiment point. It can be found from the tables that the curve turns suddenly when the ultimate load on the foundation is $1.60 \mathrm{MPa}$ and failure happens. So the ultimate load should be identified as $1.50 \mathrm{MPa}$ which is on the former point according to related standards. Two curves match identically when the pressure is less than $960 \mathrm{kPa}$ and there are no field experiment data when the load is over $960 \mathrm{kPa}$. So the parameters of $\mathrm{E}, \mathrm{v}, \mathrm{c}, \varphi$ and so on are approximate to the practice and the numerical ultimate analysis method can simulate the test of plate load to work out the complete p-s curve, which is shown in figure 3 . Since the ratio limit is less than $1 / 2$ of the ultimate capacity, $380 \mathrm{kPa}$ is identified as the eigenvalue of foundation capacity. The calculation example shows that it is conservative to take the ratio limit as the ultimate capacity of foundation. 
Table 2. Process of imposing load

\begin{tabular}{cccccccccc}
\hline Steps & 1 & 2 & 3 & 4 & 5 & 6 & 7 & 8 & 9 \\
\hline Load increment/MPa & 0.15 & 0.12 & 0.11 & 0.12 & 0.11 & 0.12 & 0.11 & 0.12 & 0.10 \\
\hline Steps & 10 & 11 & 12 & 13 & 14 & 15 & 16 & 17 & 18 \\
\hline Load increment/MPa & 0.09 & 0.05 & 0.10 & 0.10 & 0.10 & 0.05 & 0.05 & 0.025 & 0.025 \\
\hline
\end{tabular}

Table 3. FEM calculation results of pressure and settlement on the experiment point

\begin{tabular}{cccccccccc}
\hline Pressure $/ \mathrm{kPa}$ & 150 & 270 & 380 & 500 & 610 & 730 & 840 & 960 & 1060 \\
\hline Settlement $/ \mathrm{mm}$ & 3.11 & 5.75 & 8.625 & 12.25 & 15.96 & 20.48 & 24.92 & 29.92 & 34.22 \\
Pressure $/ \mathrm{kPa}$ & 1150 & 1200 & 1300 & 1400 & 1500 & 1550 & 1600 & 1625 & 1650 \\
Settlement $/ \mathrm{mm}$ & 38.20 & 40.58 & 45.41 & 50.80 & 56.84 & 60.54 & 66.00 & 70.23 & 79.78 \\
\hline
\end{tabular}

Pressure/kPa

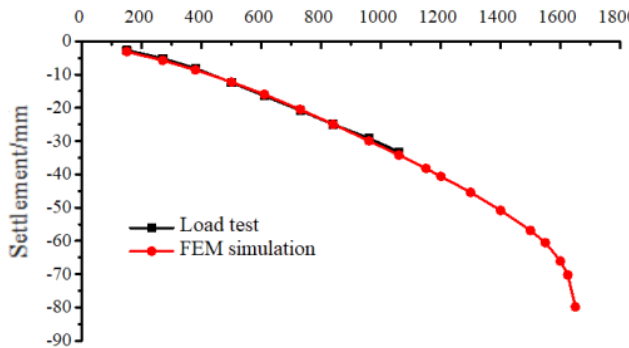

Figure 3. Comparison of $\mathrm{p}$-s curves between FEM simulation and load test

\section{Bearing capacity of foundation through the method of ultimate strain}

The ultimate strain of geo-technical materials are worked out based on the above calculation parameters and the reference 4 . Figure 4 shows the calculation model and

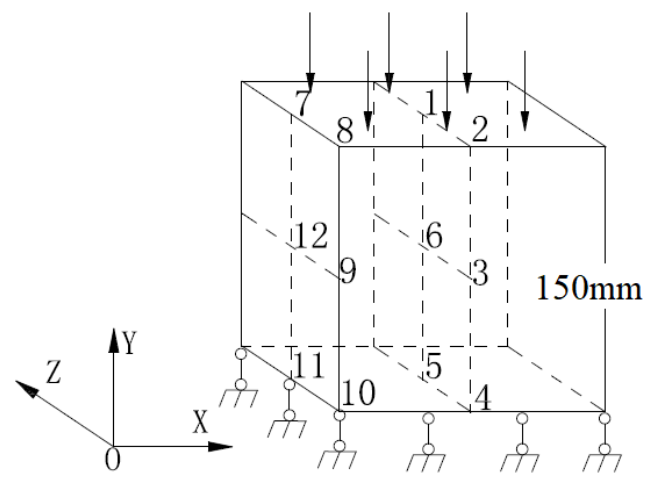

Figure 4. Calculation model of ultimate strain of geotechnical materials

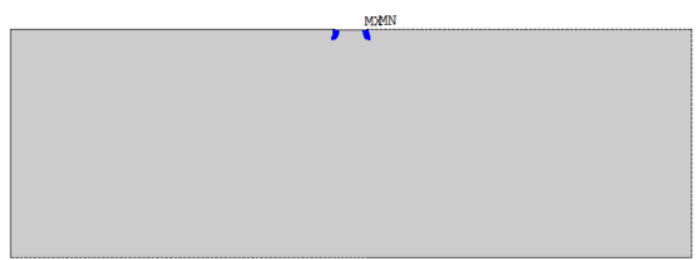

Figure 6. Nephogram of equivalent plastic strain when the load is $1.0 \mathrm{MPa}$ the ultimate load is $77.5 \mathrm{kPa}$. Figure 5 is its nephogram of equivalent plastic strain and the ultimate strain is 0.025 .

In figure 6 , failure can be identified in some points of the foundation according to ultimate strain method and cracks appear when the load is $1.00 \mathrm{MPa}$; in figure 7 , failure surfaces gradually cross when the load $\mathrm{P}=1.50 \mathrm{MPa}$; in figure 8 , failure surfaces link together and complete failure happens on the foundation when $\mathrm{P}=1.65 \mathrm{MPa}$. The ultimate load through ultimate strain method is $1.65 \mathrm{MPa}$, so the former point $1.60 \mathrm{MPa}$ can be identified as the ultimate load of foundation. Since the ratio limit is less than $1 / 2$ of the ultimate load, $380 \mathrm{kPa}$ can be still treated as the eigenvalue of the bearing capacity of foundation.

As a result, the calculation results through increment loading method and ultimate strain method are basically the same. The ultimate loads of the two method differ $3 \%$. The practical measured result tends to be small because the load test ends too early.

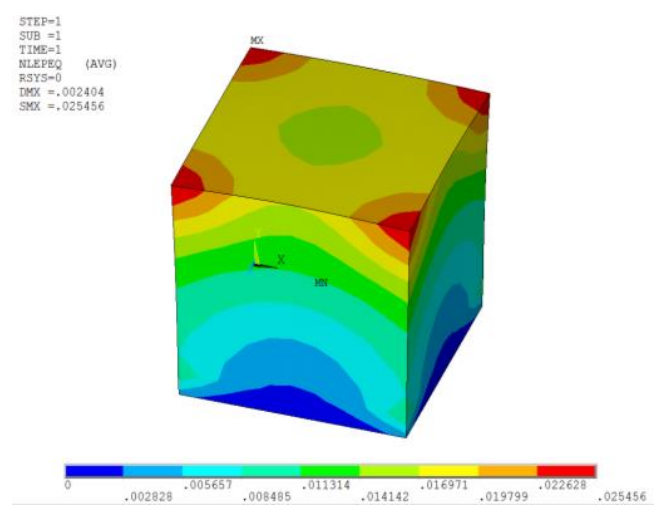

Figure 5. Nephogram of equivalent plastic strain when the load is $77.5 \mathrm{kPa}$

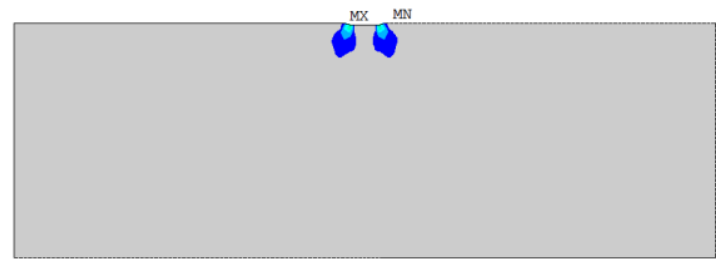

Figure 7. Nephogram of equivalent plastic strain when the load is $1.5 \mathrm{MPa}$ 


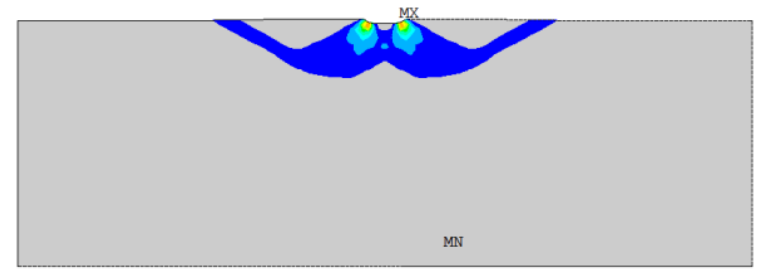

Figure 8. Nephogram of equivalent plastic strain when the load is $1.65 \mathrm{MPa}$

\section{Conclusions}

Numerical ultimate analysis can simulate the whole process of the load test effectively and the pressuresettlement curves match well. Although small discrepancy exists in the ultimate load, the reason is the different criteria to identify the ultimate load. If taking the beginning of uplift of the ground as criteria, the results are identical. Ultimate strain method takes the ultimate strain as failure criteria, which can be looked as the criteria of both failure in a point and the complete failure. Crack failures appear first at the two foot of foundation, then extend to the middle and cross together and at last extend to the two sides till link to the ground. Ultimate strain method can display the whole process of foundation failure and work out the crack load and ultimate load of complete failure.

\section{Acknowledgements}

The researching achievements of the project is supported by the Science and technology research program from Chongqing Education Committee "Researches on the damage assessment and the residual life prediction in the service period of earth-retaining wall".

\section{Introduction to the author}

Tang Xiaosong (1979-), male, doctor of engineering, vice professor, mainly studies on the stability analysis and numerical simulation of rock and soil engineering, E-mail: hnm97@163.com.

\section{References}

1. TERZAGHI K. Theoretical soil mechanics[M]. New York: Wiley, 1943: 265.

2. Zhang Yu-cheng, Yang Guang-hua, Hu Hai-ying. Discussion on size effect of plate loading test and determination of bearing capacity of subgrade[J]. Rock and Soil Mechanics, 2016, 37(Supp.2): 263272.

3. Sun Hongwei, Feng Haiyue. Analysis on computation formula for subgrade bearing capacity applied in geotechnical and foundation design[J]. Building Structure, 2015, 45(12): 101-104.

4. ABI Erdi, FENG Xiating, ZHENG Yingren. Strain Analysis and Numerical Analysis Based on Limit Strain for Geomaterials[J]. Chinese Journal of Rock Mechanics and Engineering, 2015, 34(8): 1552-1560.
5. Li Shigui, Huang Da, Shi lin. Numerical modeling of the evolution of slope failure using the limit stain criterion and dynamic strength reduction method[J]. Journal of Engineering Geology, 2018, 26(5): 12271236.

6. Zheng Yingren. Development and Application of Limit Analysis for Geological Materials[J]. Chinese Journal of Rock Mechanics and Engineering, 2012, 31(7): 1297-1315.

7. DENG Chu-jian, TANG Xiao-song, ZHENG Yingren. Numerical analysis of the plate loading test[J]. Rock and Soil Mechanics, 2007, 28(Supp.): 249-253. 